\title{
The Phonetic Characteristics in Patients of Bilateral Vocal Fold Paralysis Without Tracheotomy
}

\author{
Yong Tae Hong ${ }^{1}$ Min Ju Park² $\cdot$ Yu Jeong Shin ${ }^{3}$ Phan Huu Ngoc Minh $\cdot$ Ki Hwan Hong ${ }^{1}$ \\ Departments of ${ }^{1}$ Otolaryngology-Head and Neck Surgery and ${ }^{2}$ Speech-Language Therapy, Research Institute for Clinical Medicine, Chonbuk \\ National University and Biomedical Research Institute, Chonbuk National University Hospital, Jeonju; ${ }^{3}$ Department of Speech-Language \\ Therapy, Howon University, Gunsan, Korea
}

Objectives. Patients with bilateral vocal fold paralysis (BVFP) theoretically have difficulty producing voiceless consonants. However, perceptual studies have revealed clear production of voiceless consonants with good articulation scores in nontracheostomized patients. The purpose of this study was to clarify the production of voiceless stops during articulation in patients with BVFP compared to normal speakers.

Methods. The perceptual, acoustic, and aerodynamic characteristics of patients with BVFP and those with normal speech were investigated with special reference to voiceless stop consonants. Test words were prepared to place the stop consonants in different phonological environments, and were all nonsense words.

Results. The patients with BVFP perceptually produced the three types of stops successfully. However, they acoustically varied voice onset time to produce phonetically representative stops but decreased voice onset time of $/ \mathrm{p}^{\mathrm{h}} /$ and $/ \mathrm{p} /$ compared to those of normal speakers. These patients may properly control air pressure to produce the three types of stop consonants similar to normal speakers.

Conclusion. The patients with BVFP realized the distinctions between the three types of stops similar to the normal speakers. Although vocal mobility was absent in the patients with BVFP, voice onset time, vowel duration, closure duration, and air pressure were similar to those of normal speakers.

Keywords. Bilateral Vocal Fold Paralysis; Voice

\section{INTRODUCTION}

Vocal fold immobility is a term describing restricted unilateral or bilateral movement of the vocal folds due to mechanical fixation or neurological involvement. Two clinical patterns are observed in patients bilateral vocal fold paralysis (BVFP), such as rapid stridor to dyspnea or progressive and gradual dyspnea over a few months, but they usually have no significant changes

- Received May 10, 2016

Revised August 10, 2016

Accepted August 15, 2016

- Corresponding author: Ki Hwan Hong

Department of Otolaryngology-Head and Neck Surgery, Chonbuk National

University Hospital, 20 Geonji-ro, Deokjin-gu, Jeonju 54907, Korea

Tel: +82-63-250-1990, Fax: +82-63-250-1986

E-mail: khhong@chonbuk.ac.kr in voice quality [1,2]. BVFP treatment aims to reestablish a patent airway, preserve glottic sphincter function, and maintain voice quality. BVFP is a potentially fatal condition; thus, it needs to be diagnosed promptly and accurately and treated appropriately [3]. Existing surgical options are tracheotomy, laser arytenoidectomy, vocal fold lateralization, and laryngeal reinnervation $[4,5]$.

BVFP limits the vocal cord movements necessary for normal vocal function and changes the physiology for producing stop consonants. As a result, speech production is not supported by the abductor-adductor system, and no evidence suggests that patients with BVFP can alter the abductor-adductor system within the larynx. Normal laryngeal speakers systematically vary voice onset time (VOT) values to produce voiceless stop consonants and characterize the prevocalic stops [6]. Appropriate control of

Copyright (C) 2017 by Korean Society of Otorhinolaryngology-Head and Neck Surgery.

This is an open-access article distributed under the terms of the Creative Commons Attribution Non-Commercial License (http://creativecommons.org/licenses/by-nc/4.0)

which permits unrestricted non-commercial use, distribution, and reproduction in any medium, provided the original work is properly cited. 
abduction and adduction of the vocal folds produces various VOT values for stops. A three-way distinction exists in the manner and place of articulation of stop consonants during normal laryngeal speech in Koreans, which are classified as the unaspirated $/ \mathrm{p}^{\prime} /$, slightly aspirated $/ \mathrm{p} /$, and heavily aspirated $/ \mathrm{p}^{\mathrm{h}} /$ consonants. The $/ \mathrm{p}^{\prime} /$ stop is characterized by the completely adducted state of the vocal folds, stiffened vocal folds, and the abrupt decrease in stiffness near voice onset at explosion, and the $/ \mathrm{p}^{\mathrm{h}} /$ type is characterized by the extensively abducted state of the vocal folds and the heightened subglottal pressure at explosion [7-9]. The vocal folds during the $/ \mathrm{p} /$ stop are moderately abducted at explosion. However, patients with BVFP cannot properly adduct the vocal folds due to immobility of both vocal folds. Thus, stop production in patients with BVFP differ from that of normal laryngeal speakers due to the voicing source.

Multidimensional voice analyses in patients with BVFP include auditory-perceptual, acoustic, and aerodynamic assessment procedures. The auditory-perceptual evaluation method uses the GRBAS (grade, rough, breathy, asthenic, strained) scale and speech discrimination scores for stop consonants. The GRBAS scale of the Japan Society of Logopedics and Phoniatrics gives scores of $0,1,2$, or 3 for the grades of hoarseness, roughness, breathiness, asthenia, and strain, where 0 is normal, 1 is a slight degree, 2 is a medium degree, and 3 is a high degree $[10,11]$.

Acoustic analyses involve quantitative tests, include parameters such as pitch period perturbation, amplitude perturbation, and laryngeal noise components as well as spectrograms [12]. Unfortunately, only a few acoustic studies have been carried out in patients with BVFP, as no significant changes in voice quality occur when the airway is not compromised. Voice quality in patients with BVFP is characterized by low fundamental frequency, a highly restricted range of fundamental frequency, and a large number of pertubations of fundamental frequency, such as jitter and shimmer [2,4]. Some patients with BVFP produce a clear stops, properVOT and vowel duration, resulting in good articulation scores. However, patients with BVFP cannot theoretically produce proper VOT because they cannot appropriately control abduction and adduction of the vocal folds. Phonation has been aerodynamically assessed to quantify vocal dysfunction in patients with vocal fold paralysis [13,14]. The main purpose of this study was to clarify various parameters of perceptual, acoustic, and aerodynamic analyses in patients with BVFP, particularly

\section{H I G G H L L I}

- The patients with bilateral vocal fold paralysis (BVFP) had varied voice onset time.

- The BVFP patients might control air pressure to produce 3-typed stop consonants.

- The patients used intraoral air pressure and flow control to distinguish voiceless stop. focusing on speech production. We evaluated GRBAS scale and speech discrimination scores during running speech production, and the acoustic and aerodynamic characteristics of speech articulation with special reference to consonant production were also evaluated.

\section{MATERIALS AND METHODS}

\section{Subjects and speech materials}

We selected 10 patients with BVFP (7 females and 3 males) for this study. Selection criteria included the patients showing a proper endoscopic glottic gap for respiration. All patients have glottis gap about 3-5 $\mathrm{mm}$ on gross examination. No patients showed more than about $5 \mathrm{~mm}$ of glottic gap in this study. The patients and normal subjects were excluded when they had any past history of laryngeal surgery and recent other laryngeal disorders. The etiologies of BVFP were four cases after total thyroidectomy, two cases after esophagectomy, one case after tracheotomy, three cases of unknown etiology. All patients had proper perceptual voice quality and physical airway status. We reviewed an Institutional Review Board approval and obtained proper consent from the normal subjects.

All participants were tape-recorded at the same recording level (dBs) in a quiet room using a digital audio-tape recorder. A head-mounted Sony ECM-50 microphone (Sony, Tokyo, Japan) was held at a constant distance of $5 \mathrm{~cm}$ in front of the speaker's mouth. Test words were prepared to place the $/ \mathrm{p} /$ consonants in different phonological environments (/CVCV/ syllables; $\mathrm{C}$, consonant; $\mathrm{V}$, vowel), and all were nonsense words. The following were the test words: (1) the labial slightly aspirated (SA) stop followed by the vowel /i/, /pipi/; (2) the labial heavily aspirated (HA) stop followed by the vowel $/ \mathrm{i} /, / \mathrm{p}^{\mathrm{h}} \mathrm{ip}{ }^{\mathrm{h}} \mathrm{i} /$; (3) the labial unaspirated (UA) stop followed by the vowel /e/, /p'ip'i/. Phonation samples at comfortable pitch and loudness were recorded with repetitive phonation for the ideal signals.

\section{Perceptual analysis}

Thirty subjects (20 males and 10 females) participated in the perceptual assessments. Among them, 13 were speech therapy majors and 17 were not the assessment process and methods were explained to all participants before the psychoacoustic assessments. The sustained vowel /a/ was used for the voice samples, and it was performed twice to assess the GRBAS. A 4-point score $(0,1,2$, and 3$)$ is suggested for each character of grade $(G)$, roughness $(\mathrm{R})$, breathiness $(\mathrm{B})$, asthenia $(\mathrm{A})$, and strained $(\mathrm{S})$ in the GRBAS scale. However the midpoints of $0.5,1.5$, and 2.5 were also checked in this assessment to determine the dysphonia details. The bilabial stop consonants, / $\mathrm{p}^{\mathrm{h}} \mathrm{p}^{\mathrm{h}} \mathrm{ida} /, / \mathrm{p}^{\prime} \mathrm{ip}$ 'ida/, and /pipida/, were used for the test words in a /CVCV/ form. Stored speech samples were given to the participants without any editing. Each sample was played three times, and the partic- 
ipants were told to write down what they heard. They were told to mark ' $\mathrm{X}$ ' instead of a word if they could not determine exactly. All scoring was done individually, and the ratios of the exact written sample to the given test word were calculated.

\section{Acoustic and aerodynamic analyses}

Ten normal subjects participated to compare with the patients with BVFP. All acoustic measures were obtained using the Praat speech analysis system (http://www.fon.hum.uva.nl/praat/). This method and computer hardware/software package were selected because they are easily available, and the selected acoustic measures can be measured with little training. All speech samples were played from a digital audio-tape recorder at a constant playback level. The words tested during the phonetic analysis were sampled at $8 \mathrm{kHz}$ with 10-bit accuracy. Each word was displayed as a wide-band spectrogram and acoustic waveform, and the VOT duration in the initial position of the word (/CVCV/), vowel duration during vocal fold vibration (/Cㄷㄷ), and oral

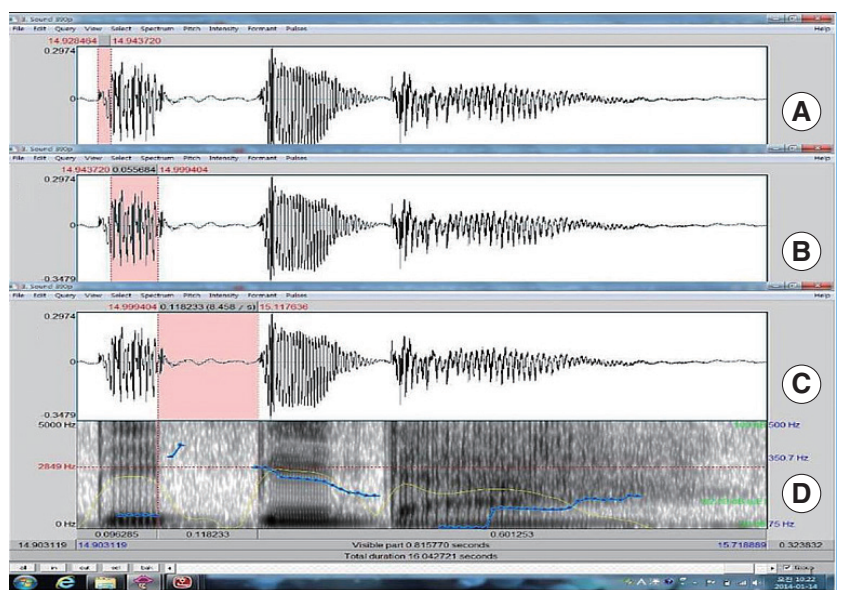

Fig. 1. Acoustic waveforms (A) for voice onset time, (B) for vowel duration, $(C)$ oral closure time, and $(D)$ wideband spectrogram during production of stop consonants /CVCV/.

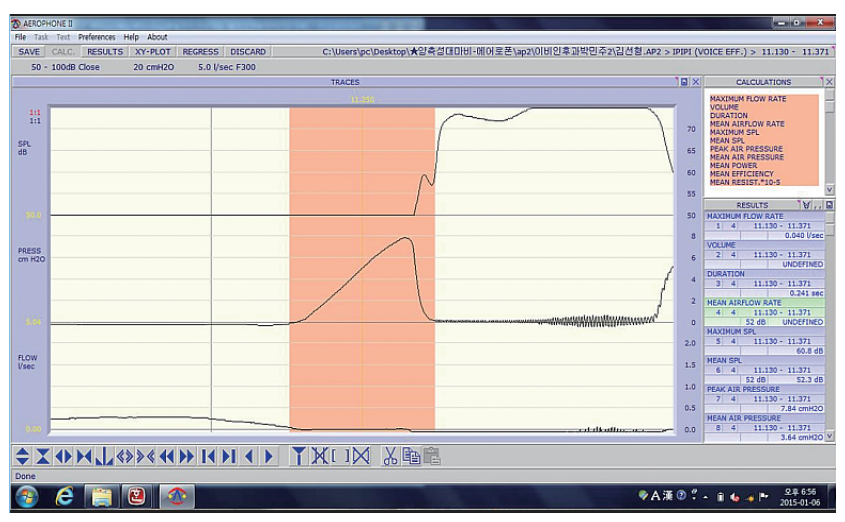

Fig. 2. Aerodynamic analysis during production of stop consonants /CVCV/, sound pressure level (SPL), oral pressure and airflow. closure time (/CVㄷ/) were measured accurately (Fig. 1). VOT in the /CVCV/ syllables was defined as the time between burst onset and the identifiable periodic vibration for the subsequent vowel within the acoustic wave. Oral closure time duration was measured as the time from offset of vowel periodicity in the speech wave to consonant burst onset (/CVㄷV/), not at the word-initial position. Participants were instructed to take the deepest breath possible and sustain /a/ as long as possible at a typical pitch and loudness to measure maximum phonation time (MPT). The longest of the three trials was recorded in seconds as the MPT. Data were collected in a double-walled soundattenuating audiology booth. The phonatory aerodynamic system (AerophoneII, KayPentax, Lincoln Park, NJ, USA) and software were used for the 10 patients with BVFP and the 10 control participants. We measured aerodynamic variables such as maximum sound pressure level (SPL), mean SPL, peak air pressure (AP), and mean AP in different phonological environments (/CVCV/ syllables) (Fig. 2).

\section{RESULTS}

\section{Perceptual findings}

The GRBAS scale, discrimination scores for stops, and Multi-Dimensional Voice Program (MDVP) scores were analyzed. Mean G, R, B, A, and S scale scores were 1.44, 1.23, 1.15, 1.10, and 1.15 and revealed mild dysphonic characteristics (Table 1, Fig. 3). The discrimination scores for the stops in the test words were $90.67 \%, 79.00 \%$, and $96.22 \%$ for $/ \mathrm{p} /, / \mathrm{p}^{\mathrm{h}} /$, and $/ \mathrm{p}^{\prime} /$. The highest score was for $/ \mathrm{p}^{\prime} /$, followed by $/ \mathrm{p} /$ and $\mathrm{p}^{\mathrm{h}} /$ (Table 2 ).

\section{Acoustic and aerodynamic findings}

Noise components were noted extensively on the wideband spectrograms and incomplete formant bands were produced during VOT (/CVCV/) (Fig. 2). The mean MDVP scores for the sustained vowel /a/ were $1.03 \%$ of jitter, $5.54 \%$ of shimmer, 0.06 of noise to harmonic ratio (NHR), $3.05 \%$ of variable $\mathrm{F} 0$

Table 1. GRBAS scale scores for the sustained vowel /a/

\begin{tabular}{cccccc}
\hline Subject & Grade & Rough & Breathy & Asthenic & Strained \\
\hline 1 & 0.75 & 0.62 & 0.83 & 1.07 & 0.95 \\
2 & 2.18 & 1.95 & 2.33 & 1.63 & 1.92 \\
3 & 1.00 & 0.67 & 0.33 & 1.50 & 0.33 \\
4 & 1.45 & 1.47 & 0.83 & 1.25 & 1.10 \\
5 & 1.57 & 1.83 & 0.92 & 1.07 & 1.93 \\
6 & 1.37 & 1.38 & 1.28 & 1.33 & 1.65 \\
7 & 1.50 & 1.50 & 1.50 & 1.00 & 0.83 \\
8 & 2.17 & 1.17 & 2.17 & 1.17 & 1.00 \\
9 & 0.83 & 0.50 & 0.50 & 0.50 & 1.50 \\
10 & 1.57 & 1.17 & 0.83 & 0.50 & 0.33 \\
Mean & 1.44 & 1.23 & 1.15 & 1.10 & 1.15 \\
\hline
\end{tabular}

GRBAS, grade, rough, breathy, asthenic, strained. 


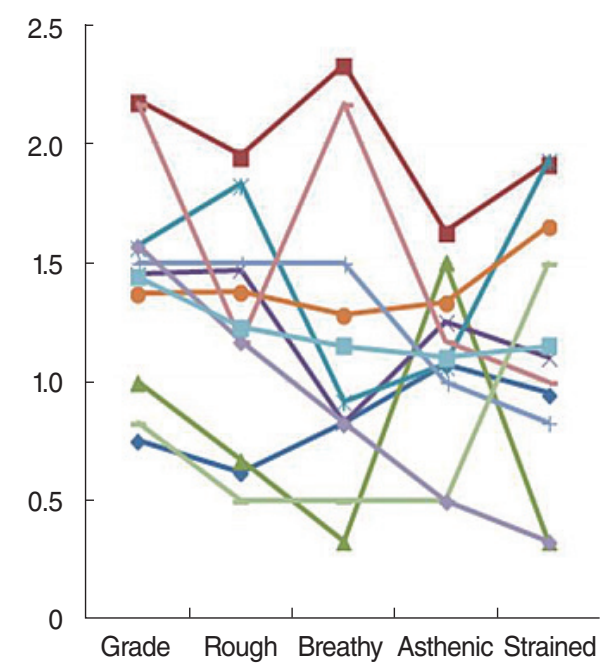

$(\%)$

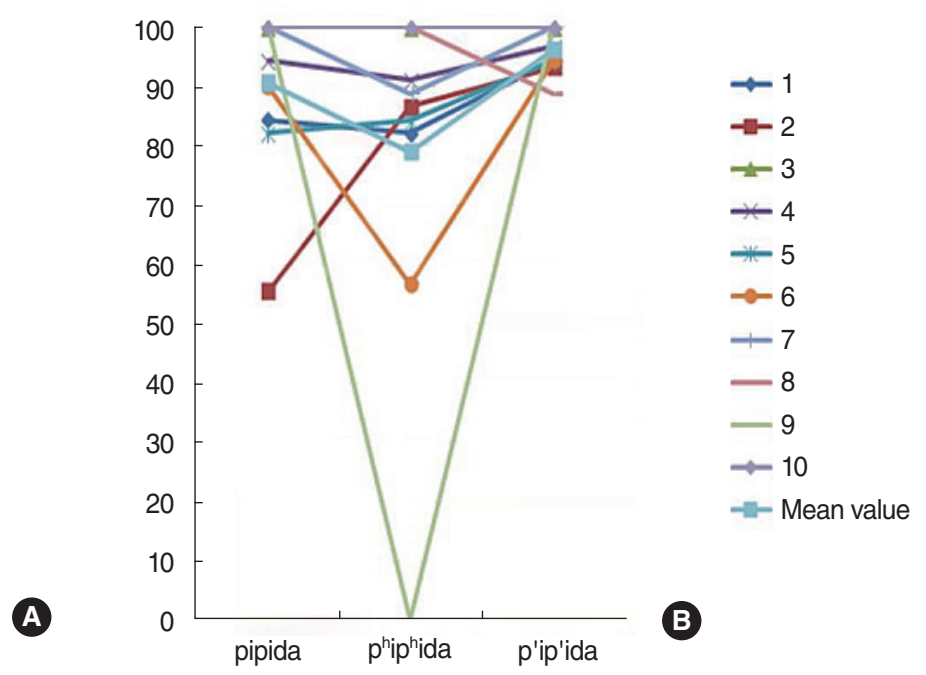

Fig. 3. (A) Distributions of grade, rough, breathy, asthenic, strained (GRBAS) scales and (B) speech discrimination scores.

Table 2. Speech discrimination scores with consonants

\begin{tabular}{|c|c|c|c|}
\hline Subject & /pipida/ & $/ p^{h} i p^{h i d a /}$ & /p'ip'ida/ \\
\hline 1 & 84.45 & 82.22 & 94.44 \\
\hline 2 & 55.55 & 86.67 & 93.33 \\
\hline 3 & 100 & 100 & 100 \\
\hline 4 & 94.44 & 91.11 & 96.67 \\
\hline 5 & 82.22 & 84.45 & 94.44 \\
\hline 6 & 90.00 & 56.67 & 94.44 \\
\hline 7 & 100 & 88.89 & 100 \\
\hline 8 & 100 & 100 & 88.89 \\
\hline 9 & 100 & 0 & 100 \\
\hline 10 & 100 & 100 & 100 \\
\hline Mean & 90.67 & 79.00 & 96.22 \\
\hline
\end{tabular}

Table 3. Characteristics of the acoustic parameters

\begin{tabular}{lcccc}
\hline Variable & Normal & Patients & $\begin{array}{c}\text { Mann-Whitney } \\
\text { U-test }\end{array}$ & $P$-value \\
\hline Jitter (\%) & 0.26 & 1.03 & 20.0 & $0.011^{*}$ \\
Shimmer (\%) & 3.73 & 5.54 & 45.5 & 0.749 \\
NHR & 0.01 & 0.06 & 50.0 & 1.000 \\
VFO (\%) & 1.52 & 3.05 & 31.5 & 0.161 \\
APQ (\%) & 3.09 & 4.32 & 49.0 & 0.965 \\
HNR (dB) & 20.85 & 18.70 & 40.0 & 0.467 \\
\hline
\end{tabular}

$\mathrm{HNR}$, harmonics to noise ratio; $\mathrm{VFO}$, variable FO; $\mathrm{APQ}$, amplitude perturbation quotient.

${ }^{*} P<0.05$.

(vF0), $4.32 \%$ of amplitude perturbation quotient (APQ), and $18.70 \mathrm{~dB}$ of HNR (dB) (Table 3).

Normal VOT values for the $/ \mathrm{p}^{\prime} /$ type stop consonant in the normal subjects were $9.4 \mathrm{msec}$ of the burst, about $55.5 \mathrm{msec}$ in the $/ \mathrm{p} /$, and $60.7 \mathrm{msec}$ in the $/ \mathrm{p}^{\mathrm{h}} /$ (Table 4). The mean VOT values for the patients with BVFP were $43.5 \mathrm{msec}$ in the /p/, $46.2 \mathrm{msec}$ in the $/ \mathrm{p}^{\mathrm{h}} /$, and $12.7 \mathrm{msec}$ in the $/ \mathrm{p}^{\prime} /$. A decrease in VOT was detect-
Table 4. Acoustic characteristics of the stop consonants

\begin{tabular}{lcccc}
\hline Variable & Normal & Patients & $\begin{array}{c}\text { Mann-Whitney } \\
\text { U-test }\end{array}$ & $P$-value \\
\hline $\begin{array}{l}\text { MPT (sec) } \\
\text { VOT (msec) }\end{array}$ & 13.0 & 8.1 & 22.0 & $0.032^{*}$ \\
pi & 55.5 & 43.5 & 36.0 & 0.306 \\
$p^{\text {hi }}$ & 60.7 & 46.2 & 15.0 & $0.006^{* *}$ \\
$p^{\prime} i$ & 9.4 & 12.7 & 41.5 & 0.536 \\
VD (msec) & & & & \\
$p^{\text {hi }}$ & 56.3 & 61.1 & 39.0 & 0.422 \\
$p^{\prime} i$ & 74.3 & 78.0 & 41.5 & 0.541 \\
CD (msec) & & & & \\
$p^{h} i$ & 112.0 & 128.3 & 47.0 & 0.853 \\
$p^{\prime} i$ & 128.3 & 132.9 & 43.0 & 0.631 \\
\hline
\end{tabular}

MPT, maximum phonation time; VOT, voice onset time; VD, vowel duration; $\mathrm{CD}$, closure duration.

${ }^{\star} P<0.05 .{ }^{* \star} P<0.01$.

ed for $/ \mathrm{p}^{\mathrm{h}} /$ and $/ \mathrm{p} /$ by the patients with BVFP compared to that of the normal speakers. The oral formants were normal during vowels $(/ \mathrm{CVCV} /)$ and oral closure times were also normal (/CVㄷ/). Mean vowel duration in the patients with BVFP was $61.1 \mathrm{msec}$ in the $/ \mathrm{p}^{\mathrm{h}} /$ and $78.0 \mathrm{msec}$ in the $/ \mathrm{p}^{\prime} /$, and these were similar to those of the normal speakers. The vowel duration of the $/ \mathrm{p} /$ consonant was not measured because of the voiced /b/ phenomenon of the voiceless $/ \mathrm{p} /$ in the medial word position (/CVEV/). However, the /pi/ consonant appeared as a voiced or voiceless consonant in the patients with BVFP. The mean oral closure time values for the patients with BVFP were $128.3 \mathrm{msec}$ in the $/ \mathrm{p}^{\mathrm{h}} /$ and $132.9 \mathrm{msec}$ in the $/ \mathrm{p}^{1} /$ and were similar compared to those of the normal speakers. Oral closure time of the lenis consonant was not measured in normal speakers because of the voiced /b/ phenomenon of voiceless /pi/ in the medial word position (/CVㄷV/). However, the /p/ consonant appeared as a voiced 
Table 5. Aerodynamic characteristics of the stop consonants

\begin{tabular}{|c|c|c|c|c|c|c|}
\hline \multirow{2}{*}{ Variable } & \multicolumn{2}{|c|}{ /pi/ } & \multicolumn{2}{|c|}{$/ \mathrm{p}^{\mathrm{h}} \mathrm{i} /$} & \multicolumn{2}{|c|}{ /p'i/ } \\
\hline & Normal & Patients & Normal & Patients & Normal & Patients \\
\hline Maximum SPL (dB) & 65.3 & 67.0 & 64.9 & 68.3 & 67.2 & 68.6 \\
\hline Mean SPL (dB) & 55.2 & 55.9 & 56.2 & 57.6 & 53.3 & 55.0 \\
\hline Peak AP $\left(\mathrm{cmH}_{2} \mathrm{O}\right)$ & 7.7 & 9.3 & 9.5 & 10.9 & 9.1 & 8.9 \\
\hline Mean AP $\left(\mathrm{cmH}_{2} \mathrm{O}\right)$ & 3.3 & 4.0 & 4.1 & 5.1 & 4.9 & 4.5 \\
\hline
\end{tabular}

SPL, sound pressure level; AP, air pressure.

or voiceless consonant in the patients with BVFP.

The maximum SPL measurements were $67.0 \mathrm{~dB}$ in the $/ \mathrm{pi} /$, $68.3 \mathrm{~dB}$ in the $/ \mathrm{p}^{\mathrm{h}} /$, and $68.6 \mathrm{~dB}$ in the $/ \mathrm{p}^{\prime} /$ for the patients with BVFP and were similar to SPLs of normal speakers. Mean SPLs were $55.9,57.6$, and $55.0 \mathrm{~dB}$ for the $/ \mathrm{p} /, \mathrm{p}^{\mathrm{h}} /$, and $/ \mathrm{p}^{\prime} /$ consonants in the patients with BVFP and were also similar to those of normal speakers. Peak AP values were 9.3, 10.9, and $8.9 \mathrm{cmH}_{2} 0$ for the $/ \mathrm{p} /, \mathrm{p}^{\mathrm{h}} /$ and $/ \mathrm{p}^{\prime} /$ consonants in the patients with BVFP. The mean AP values were 4.0, 5.1, and $4.5 \mathrm{cmH}_{2} 0$ for the /p/, ph/,

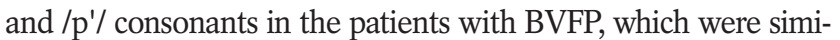
lar to the APs in normal speakers (Table 5).

\section{DISCUSSION}

Bilateral vocal fold immobility refers to all forms of limited or the absence of movement of both vocal folds. BVFP is mainly neurologically caused and specifically refers to abnormal function of the vagus nerve or the recurrent laryngeal nerve, which is its distal branch [1-4]. Bilateral vocal fold immobility may also result from mechanical problems with the laryngeal structures, such as the cricoarytenoid joint. Benninger et al. [15] attributed vocal fold immobility in a series of 117 cases to surgical trauma (44\%), malignancy (17\%), endotracheal intubation (15\%), neurological disease $(12 \%)$, and idiopathic causes $(12 \%)$.

The initial stage of BVFP may include dysphonia because the vocal folds are too far apart. However, the vocal folds move to a medial position over time, and the patient may have a relatively good voice even though they show bilateral vocal fold immobility $[4,15]$. In our study, the patients with BVFP produced three types of stops successfully. They showed abnormal voice quality acoustically and slightly abnormal pitch perturbation and noise levels. However, they varied VOT to produce phonetically representative stops but had proper vowel and closure duration times.

BVFP symptoms onset can be acute, subacute, or chronic. The voice improves as the vocal folds migrate toward the midline but the airway worsens. Thus, it is important not to mistake a good voice and cough as signs of a functioning larynx, particularly in a patient with stridor. Aspiration and dysphagia may or may not be present in patients with BVFP. Thus, a complete history is very important. The history should include airway compromise, dysphonia, and swallowing problems. Other causative events such as intubation, surgery, or other medical conditions that can affect vocal cord mobility should be discovered. Only patients with severe bilateral vocal fold immobility require surgical intervention, such as tracheotomy, and various procedures for the vocal folds or arytenoid cartilage [3,4]. Normal Korean stop consonants are classified into three types according to the manner of articulation, such as unaspirated $/ \mathrm{p}^{\prime} /$, slightly aspirated $/ \mathrm{p} /$, and heavily aspirated / $/ \mathrm{p}^{\prime} / \mathrm{stops}$. Both the $/ \mathrm{p}^{\mathrm{h}} /$ and $/ \mathrm{p}^{\prime} /$ types are always voiceless in any environment [9]. The /p/ type is voiced in the word-medial position when both the preceding and following sounds are voiced, but they are voiceless in other environments. The length of time from articulatory explosion to voice onset is the VOT. This time can be measured spectrographically from release of consonant burst to onset of the following vowel. The VOT of the / $/ \mathrm{p}^{\prime} /$ type is within $20 \mathrm{msec}$ of the burst, about 40-50 msec in the SA, and 50-70 msec in the $/ \mathrm{p}^{\mathrm{h}} /[6,8]$. Many efforts have been made to clarify the properties that differentiate these categories, including acoustic, fiberscopic, aerodynamic, and electromyographic studies. Kagaya [7] reported fiberscopic and acoustic studies of the Korean stops. He characterized the $/ \mathrm{p}^{\prime} /$ type as a completely adducted state of the vocal folds, stiffened vocal folds with an abrupt decrease in stiffness near voice onset, increasing subglottal pressure, and/or lowering of the glottis before explosion, whereas the $/ \mathrm{p}^{\mathrm{h}} /$ type was characterized by an extensively abducted state of the vocal folds and heightened subglottal pressure. In contrast, none of these positive gestures are observed for the /p/ type. Hong et al. [8] studied electromyographic activity of the thyroarytenoid and posterior cricoarytenoid (PCA) muscles during stop production. They reported marked and early activation of the PCA muscle associated with steep reactivation of the thyroarytenoid muscle before voice onset during production of the $/ \mathrm{p}^{\mathrm{h}} /$ consonant. Little or no activation of the PCA muscle was detected when producing the $/ \mathrm{p}^{\prime} /$ consonant and the earliest and most marked reactivation of the thyroarytenoid muscle was characteristic. They reported more moderate activation of the PCA muscle for the /p/ consonant than that for the $/ \mathrm{p}^{\prime} /$ consonant and the least and latest reactivation of the thyroarytenoid muscle.

In this study, the VOT values of the patients with BVFP were similar to those found during normal speech; longest in the $/ \mathrm{p}^{\mathrm{h}} /$ and $/ \mathrm{p} /$ stops and shortest in the /p'i/ stop. These mean VOT values for the $/ \mathrm{pi} /$ and $/ \mathrm{p}^{\mathrm{h}}$ / stops in the patients with BVFP are sufficient for achieving voiceless stops and quite important cues for distinguishing voiceless stop. These results mean systematic varia- 
tions in the timing of voice onset during stop production, and the VOT values associated with the production of prevocalic voiceless stops exhibit lags similar to those used by normal speakers. Although the patients with BVFP do not have use of the abductor-adductor system of the phonatory apparatus, these patients may have differences in VOT. The /pi/ and /p'i/ stops of normal speakers differed primarily in terms of a gradual versus a relatively rapid intensity build-up of the subsequent vowel after the stop release. Lee and Smith [14] measured intraoral AP simultaneously during production of the three kinds of stops. They found that subglottal pressure was higher for the $/ \mathrm{p}^{\mathrm{h}} /$ stop than for the other two stops. They also compared the dynamic pattern of the subglottal pressure slope for the three categories and found that the HA stop showed the most rapid increase in subglottal pressure in the time period immediately before stop release. We suggest that patients with BVFP might properly control subglottic pressure to produce the three types of stop consonants.

It is well known that vowel duration is conditioned by the voicing features of their consonant contexts. Hong et al. [9] reported that vowel durations after explosion of the normal Korean $/ \mathrm{p}^{\mathrm{h}} /$ and $/ \mathrm{p}^{\prime} \mathrm{i} /$ stops were not different, but the /pi/ stop could not be measured due to the voiced /b/ phenomenon. In our study, vowel durations for stops in the patients with BVFP were consistently similar to those of the normal speakers. The /pi/ stop showed a voiced or voiceless phenomenon during speech of patients with BVFP and had similar duration to that of other stops when it was voiceless. These vowel duration data suggest that patients with BVFP presumably make compensatory adjustments in the timing control system to realize these variations in vowel length before voiceless consonants. The oral closure duration is called "phonation-off time," and includes both consonant closure and release. Phonation-off times in normal Korean speech are about $160 \mathrm{msec}$ for the $/ \mathrm{p}^{\mathrm{h}} /$ and $/ \mathrm{p}^{\prime} / \mathrm{stops}$, but are not shown for the /pi/ stop due to the voiced /b/ phenomenon in the word medial position [8]. Our results show similar phonation-off times for $/ \mathrm{p}^{\mathrm{h}} /$ and $/ \mathrm{p}^{\prime} /$ in the patients with BVFP than those of the normal speakers. These values also are quite important cues for distinguishing the voiceless stop.

In summary, we have two major phonetic findings. First, the patients with BVFP systematically varied VOT to produce phonetically representative stops, and the general pattern of these variations paralleled that observed in the normal speakers. Second, the patients with BVFP had similar longer vowel and closure duration values than those of the normal speakers. Third, the patients with BVFP may properly control AP to produce the three types of stop consonants similar to that of normal speakers. We suspect that proper control of intraoral AP and airflow in the patients with BVFP is used to distinguish the voiceless stop. This study contributes to the future research on the mechanisms of proper speech production of the patients with BVFP.

\section{CONFLICT OF INTEREST}

No potential conflict of interest relevant to this article was reported.

\section{ACKNOWLEDGMENTS}

This paper was supported by fund of Research Institute for Clinical Medicine, Chonbuk National University and Biomedical Research Institute, Chonbuk National University Hospital, Jeonju, Korea.

\section{REFERENCES}

1. Rosenthal LH, Benninger MS, Deeb RH. Vocal fold immobility: a longitudinal analysis of etiology over 20 years. Laryngoscope. 2007 Oct;117(10):1864-70.

2. Chen HC, Jen YM, Wang CH, Lee JC, Lin YS. Etiology of vocal cord paralysis. ORL J Otorhinolaryngol Relat Spec. 2007;69(3):167-71.

3. Nuutinen J, Karja J. Bilateral vocal cord paralysis following general anesthesia. Laryngoscope. 1981 Jan;91(1):83-6.

4. Sapundzhiev N, Lichtenberger G, Eckel HE, Friedrich G, Zenev I, Toohill RJ, et al. Surgery of adult bilateral vocal fold paralysis in adduction: history and trends. Eur Arch Otorhinolaryngol. 2008 Dec; 265(12):1501-14.

5. Pinto JA, Godoy LB, Marquis VW, Sonego TB, Leal Cde F. Bilateral vocal fold immobility: diagnosis and treatment. Braz J Otorhinolaryngol. 2011 Sep-Oct;77(5):594-9.

6. Hong KH, Seiji N, Hajime H. Laryngeal adjustments for Korean stops, affricates and fricatives: an electromyographic study. Annu Bull Res Inst Logop Phoniatr. 1991;25:17-31.

7. Kagaya R. A fiberscopic and acoustic study of the Korean stops, affricates and fricatives. J Phon. 1974;2:161-80.

8. Hong KH, Chon DS, Kim YJ, Jung KY. Laryngeal adjustments for Korean stops: acoustic, electromyographic and fiberscopic analysis. Korean J Otolaryngol-Head Neck Surg. 1992 Dec;35(6):770-82.

9. Hong KH, Kim HK, Niimi S. Laryngeal gestures during stop production using high-speed digital images. JVoice. 2002 Jun;16(2):207-14.

10. De Bodt MS, Wuyts FL, Van de Heyning PH, Croux C. Test-retest study of the GRBAS scale: influence of experience and professional background on perceptual rating of voice quality. JVoice. 1997 Mar; 11(1):74-80.

11. Uloza V, Saferis V, Uloziene I. Perceptual and acoustic assessment of voice pathology and the efficacy of endolaryngeal phonomicrosurgery. JVoice. 2005 Mar;19(1):138-45.

12. Jiang JJ, Zhang Y, MacCallum J, Sprecher A, Zhou L. Objective acoustic analysis of pathological voices from patients with vocal nodules and polyps. Folia Phoniatr Logop. 2009;61(6):342-9.

13. Solomon NP, Helou LB, Makashay MJ, Stojadinovic A.Aerodynamic evaluation of the postthyroidectomy voice. J Voice. 2012 Jul;26(4): 454-61.

14. Lee CY, Smith TS. Oral and direct subglottal pressure in Korean stops. J Acoust Soc Am. 1972;51:102.

15. Benninger MS, Gillen JB,Altman JS. Changing etiology of vocal fold immobility. Laryngoscope. 1998 Sep;108(9):1346-50. 